\title{
Design and Construction of One-stop Virtual Experiment Platform
}

\author{
Nan-yue YANG $^{1, a, *}$ \\ ${ }^{1}$ Industrial Training Center, Guangdong Polytechnic Normal University, \\ Guangzhou 510665, China \\ aannyyang2000@163.com
}

Keywords: Information technology, Practice teaching, Virtual Reality (VR) technology, Virtual experiment platform, Education resource repository.

\begin{abstract}
The problems existing in the practice teaching of the current vocational education cause students to make practice difficultly, such as experiment instrument and equipment is outdated and limited in quantity, some experiments involve danger, and experimental process is untraceable and so on. In order to solve these problems, we build a comprehensive practice platform through information technology, which is called the one-stop virtual experiment platform. We give the design scheme of the one-stop virtual experiment platform and introduce its advantage. After analyze the structure of the one-stop virtual experiment platform in detail, we describe the implementation of it. Practice has proved that this platform is a product of deep integration of information technology and practice teaching in education. It not only provides an innovative mode to solve the problems in current vocational education, but also serves as a shared and open education resource repository for all the students and educators.
\end{abstract}

\section{Introduction}

The arrival of the information age brings Chinese vocational education new chances, which has entered the stage of rapid development [1]. Different from ordinary education, vocational education is employment oriented, so skill education is the core of it, especially the professional, practical, operational and technical training playing an important role in the teaching process [2]. However, there are some problems existing in the practice teaching of the current vocational education:

\section{Experiment Instrument and Equipment is Outdated and Limited in Quantity}

Most experimental training equipment is expensive, limited in quantity and has serious loss, and it is often obsolete, backward and difficult to keep up with the times. But the increase of the demand of society for skilled personnel made vocational colleges continue to expand enrollment, which resulted in the contradiction between the limited experimental resource and the educational need of large-scale students.

\section{Some Experiments Involve Danger}

Some teaching process involves high risk or extreme environmental skill, such as nuclear power plants and coal mining. Some involve the operation of non-reversible condition, such as heart bypass surgery and coal production process. Others involve high cost, high consumption, and large-scale comprehensive operation, such as the construction of ship and aircraft engine assembly. For all of these professional operations, schools cannot often carry out training because of lacking in effective training resource. 


\section{Experiment Teaching Resource is Scattered and Incoherent}

Subject to the content of course, the corresponding experiments or business cases make students only focus on special skill training but ignore the overall skill training, which led to their lack of industry thinking, employment flexibility and adaptability. In addition, the current teaching resource is scattered and incoherent, lacking informationalized and systematized processing, so they cannot form an organic whole, which results in that some outstanding teaching resource cannot be passed down and continue to be applied.

\section{The Existing Experiment Process is Untraceable}

The existing experiment and training have no specialized instrument or software to record and track students' operation, let alone feedback the real-time result. Furthermore the evaluation system is simple, which cannot give the students advice and approach of how to revise, improve and perfect their skill.

The above-mentioned facts lower the quality of vocational education teaching, as well as make vocational education cannot achieve the original goal of improving students' vocational skill and cultivating students' professional quality [3-4].

On the other hand, as information age coming, many vocational colleges or universities begin to carry out information construction. But it is a great pity that they only stay in the stage of applying multimedia courseware to show the teaching content or just upload some teaching resource on the website, which give less help to improve students' practical ability and develop their vocational skill indeed.

To solve the above mentioned problems, we build a comprehensive practice platform through information technology. We give the design scheme of the one-stop virtual experiment platform and introduce its advantage. Then, we analyze the structure of the platform in detail. Finally, we describe the implementation of it. With virtual reality (VR) technology, the platform runs as the open and safe lab for students making practice anytime and anywhere. Since the one-stop virtual experiment platform is also a comprehensive platform, students can take learning, training and testing on it. As all education recourse is digitalized and shared on the platform, it is accessible to the students distributed in different places. The innovations of this paper are as follow: 1) We propose and build a comprehensive practice platform with information technology which integrates teaching, learning and testing to solve the problems of the difficulty of student practice. It is an innovative mode for practice teaching. 2) Since the one-stop virtual experiment platform is a product of deep integration of information technology and practice teaching, it not only solves the existing problems in vocational education, but also serves as a shared and open educational resource repository for all the students and educators.

\section{The Design Scheme of the One-stop Virtual Experiment Platform}

The rapid development of network technology and information technology facilitates the vocational education. That is to say, through fully integrating information technology into the practice teaching process, teaching content, teaching mode, teaching quality evaluation and so on, and vocational education could offer the open informationalized recourse to students without the limitation of space and time. Therefore, we construct the one-stop virtual experiment platform via VR technology, one of the emerging information technologies, to solve the above-mentioned 
problems. The design scheme of the one-stop virtual experiment platform is as follows:

\section{Create Virtual Experiment and Training Environment}

VR technology, also called three dimensional visualization technology, can create 3D visual teaching and learning environment. Therefore, with this technology, the problem of the difficulty of student practice can be solved, such as the experimental equipment may be expensive, obsolete, serious loss, limited in quantity, some experiments involve high risk, high cost, high consumption, large-scale comprehensive operation, or some experimental condition may be tough, nonreversible and so on. Through VR technology, virtual teaching and training scene is built and thus students could carry out experiments or make practice in the $3 \mathrm{D}$ visual environment anytime and anywhere they like. When doing virtual experiments or training, students needn't consider risk, cost and consumption of experiments, including quantity or damage of equipment [5-6]. In short, VR technology makes up for the lack of physical training resource.

\section{A Comprehensive Platform Integrates Teaching, Learning and Testing}

With VR technology, students can do experiments or be trained in the virtual environment. But before making the practice, students want to know the relative knowledge of experiments and training, and they also need to understand how to conduct experiments, i.e. operating procedure. After experiments, students want to know how they do, the feedback and the guidance from their teacher. On the other hand, teachers not only want to know the result of experiments done by students but also want to know the detail of experiment process. Therefore, the virtual experiment platform should be designed to a comprehensive one for practice, namely one-stop virtual experiment platform which can provide teaching, learning and testing together for students, as well as teachers (Figure 1). On the one-stop virtual experiment platform, students may practice in example, execute training task, learn by doing and take the practice test just like in the real classroom, training base and social position [5-6]. Since the platform can track the operation of experimenters and give them realtime feedback and evaluation, students may get guidance anytime, such as the advice of how to correct operation error, how to improve and perfect their skill. The topology structure of the teaching system is shown as Figure 2.

\section{The Platform Serves As a Shared Education Recourse Repository}

As information age coming, more and more educational resource is being digitized, which is spread and shared via Internet easily, conveniently and rapidly. In order to be used widely, the one-stop virtual experiment platform must be a digital repository for vocational education resource [1]. Information technology is applied to vocational teaching process, teaching content, teaching method and teaching quality evaluation, so various digital resources such as network courses, multimedia courseware, process simulation software, etc., are gathered in the platform and thus form a resource repository. Students can take professional lesson, practice training, case analysis and skill identification exam, etc., on the platform with this digital resource. In addition, all this vocational education resource on the platform is easily updated and shared for students scattered in different places through Internet. In order to keep pace with the times, as a digital repository, the one-stop virtual experiment platform must be designed to be easy to expand and further develop for adding new content and new function. 


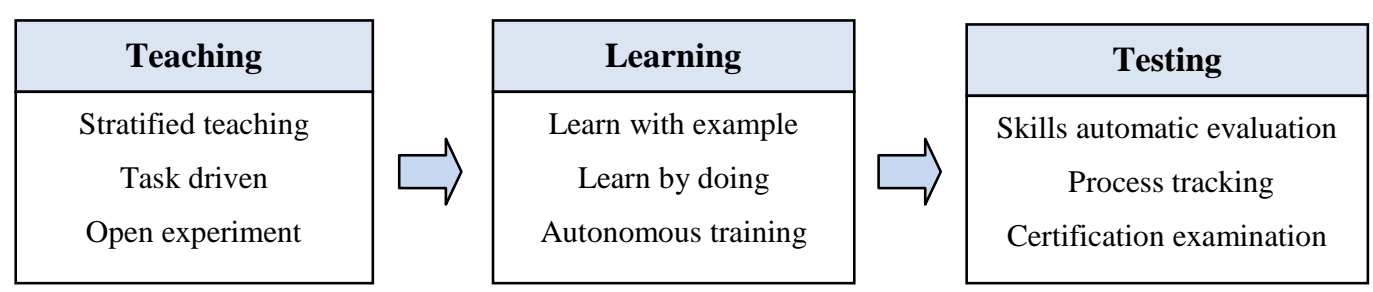

Figure 1. The Comprehensive Virtual Experiment Platform

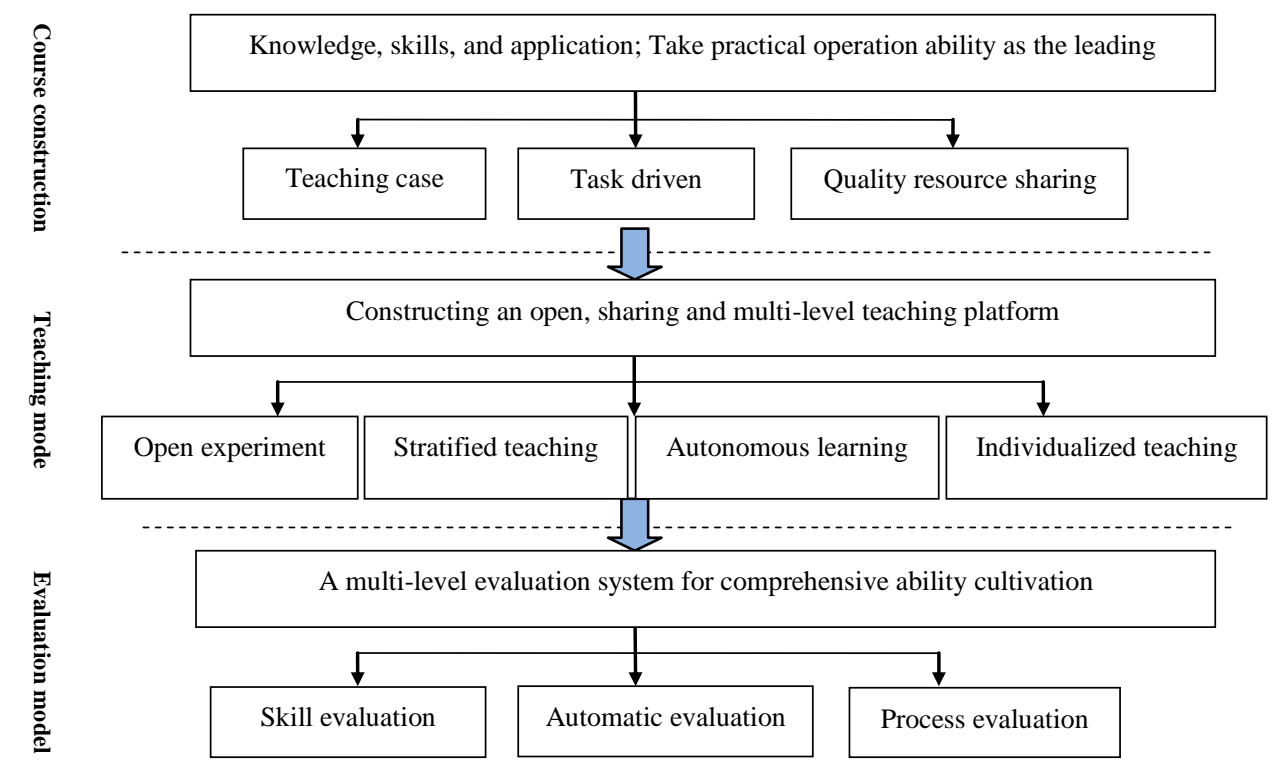

Figure 2. The Topology Structure of the Teaching System

\section{The Advantages of the One-stop Virtual Experiment Platform}

\section{Run as the Open and Safe Lab}

VR technology facilitates the execution of different kinds of experiments and training. On the one-stop virtual experiment platform, students carry out virtual practice without the restriction of space and time just like in the open lab. Furthermore, the dangerous experiments are replaced by the virtual experiments, such as the experiments which emit toxic gases, involve dangerous operation and tough condition, so all the experiments on the platform are safe. When doing experiments in the virtual world, students don't need to worry that the equipment will be damaged. In short, the one-stop virtual experiment platform runs as the open and save lab for students [7].

\section{A Comprehensive Experiment Platform}

The one-stop virtual experiment platform is a comprehensive one that integrates teaching, learning and testing for students and teachers. On the platform, students learn knowledge and train their skills in the vivid virtual environment. When they make practice, they interact with the virtual experimental objects, learning resource, teachers and other classmates on line and then get real time feedback or effective guidance from them. Students not only take learning and training on the platform, but also take different types of test, such as operation exam, professional competition and skill identification exam and so on, which may give them skill evaluation or grade identification. For teachers, the platform is a comprehensive teaching environment 
which integrates classroom, laboratory, training base, factory and company, etc., into the virtual world. Teachers could give students guidance, make course construction or do some scientific research on the platform at any time.

\section{A Shared Education Resource Repository}

All education recourse, including network course, audio and video excellent courseware, enterprise case demo, etc., in the one-stop virtual experiment platform is shared and open to be further constructed. Teachers, educators and students can share the existing digital achievements or develop new information resource via Internet anytime anywhere [8]. The one-stop virtual experiment platform serves as a shared education recourse repository for all the users on line [9].

\section{The Composition of the One-stop Virtual Experiment Platform}

According to the design scheme mentioned before, the one-stop virtual experiment platform is a comprehensive one that integrates teaching, learning and testing, so it is composed of experiment management system, experiment teaching system, autonomous learning system and automatic test system. The detailed structure of the one-stop virtual experiment platform is shown as Figure 3.

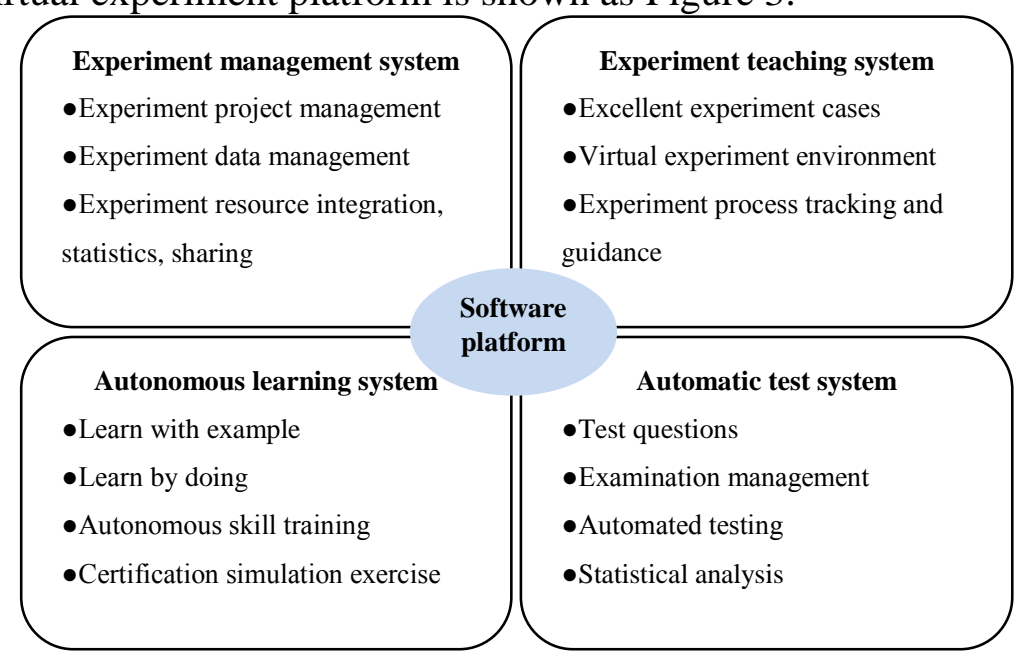

Figure 3. Structure of the One-stop Virtual Experiment Platform

\section{Experiment Management System}

The experiment management system includes the notification system, user management, user group management, role management and authority management, etc. It is responsible for the general management of various experiment resources, experiment information, user information and so on, which makes the experiment management operate scientifically, intelligently and efficiently.

\section{Experiment Teaching System}

The experiment teaching system includes two parts: resource sharing module and experiment teaching module. It provides the open experiment environment for resource sharing, experiment teaching, assignment management and experiment teaching evaluation, which makes the experiment teaching run efficiently.

Resource sharing module provides high available and high quality resource, such as teaching case, courseware, excellent course, micro course, and enterprise case, etc., which are categorized for easy retrieval. All the resource is open and shared, and can 
be expanded and developed independently, so they will gradually form a complete education recourse repository.

Experiment teaching module creates a highly interactive virtual environment for experiment teaching through VR technology, and it also provides experiment process tracking and targeted guidance. Moreover, it includes the function of experiment task release, recovery and evaluation, as well as excellent work display and sharing [10]. The experiment teaching process is shown in Figure 4.

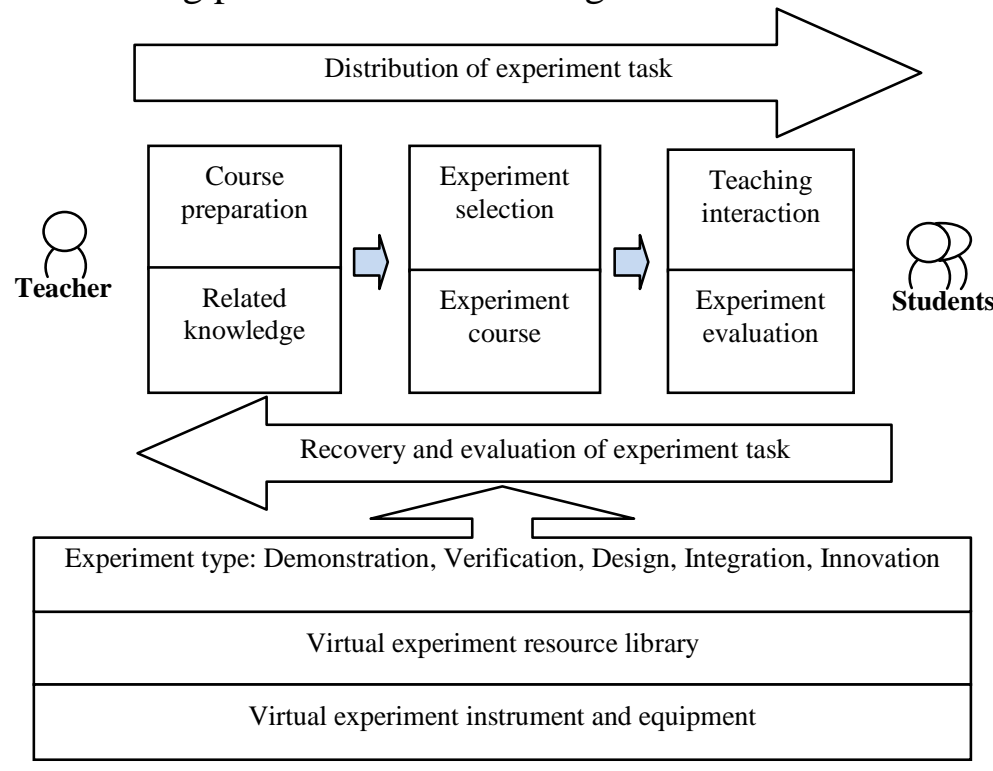

Figure 4. Experiment Teaching Process

\section{Autonomous Learning System}

The autonomous learning system includes ten modules: login module, knowledge presentation, resource integration, learning tool, online test, online operation, realtime discussion area, special discussion area, learning process record and query. It not only provides rich experiment cases and highly interactive virtual environment for students to carry out experiments, but also tracks students' operation process and offers real-time evaluation. If students make improper operation, it will give them study proposal or correct operation demonstration, which realizes one to one teaching guidance [11].

The process of autonomous learning is: (1) Student logs in the system. The learning process record module begins to track the study trajectory of the student. (2) Student obtains learning task from knowledge presentation module and then learn in example provided by the resource integration module, such as professional case, operation video of real environment, etc. (3) When student encounters the problem he does not understand, he may consult in the query module or learn by doing interactive operation in virtual environment via the learning tools module. (4) Whether the student performs online learning or do homework or test, the autonomous learning system will give him real-time feedback and evaluation, including hint information and operational demonstration, until he eventually masters the correct operation skill and method. (5) The system analyses this autonomous learning and gives student suggestion for further study. Autonomous learning process is shown in Figure 5. 


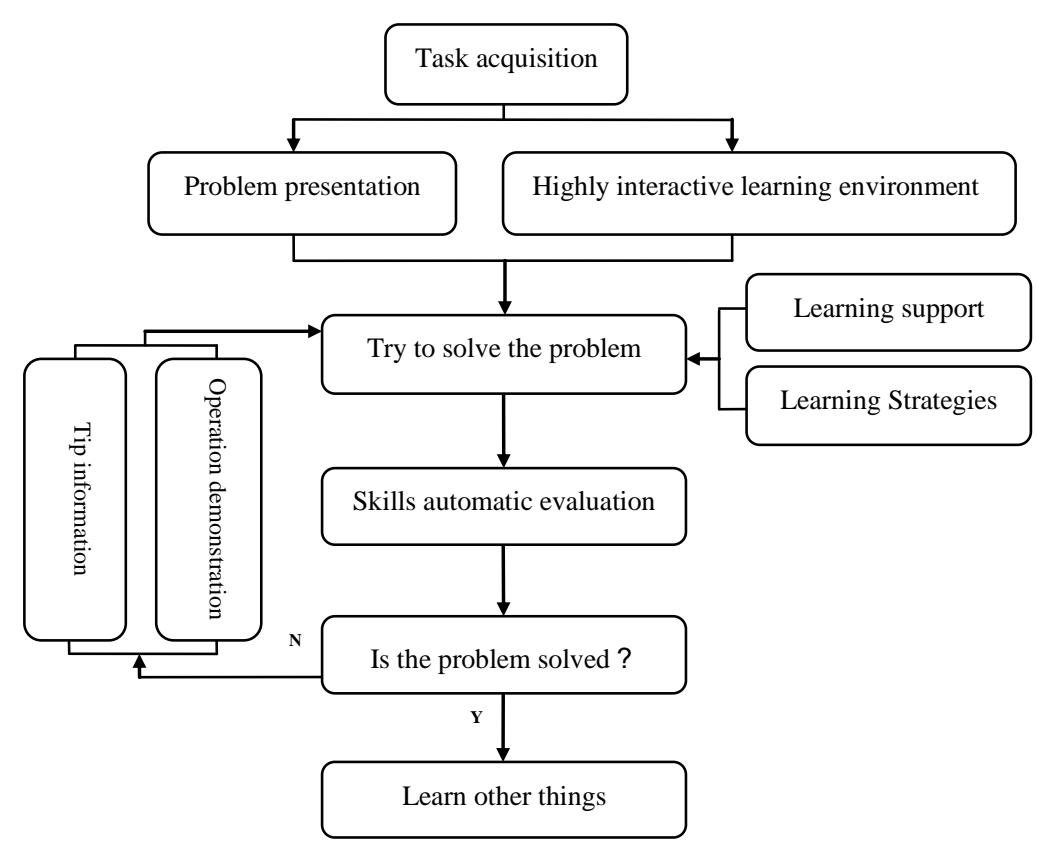

Figure 5. Autonomous Learning Process

\section{Automatic Test System}

The automatic test system is established based on the skill evaluation. It is a diversified evaluation system. In this system, a variety of evaluation methods are adopted to meet different demands according to the scientific evaluation mechanism [12], such as job evaluation, experiment process evaluation and skill identification evaluation and so on.

The automatic test system provides skill training and assessment in the real environment of simulation, which can investigate the actual operation level of the operator. In addition, the system possesses user-defined test, so students can choose test paper from exam-paper database at random or by themselves. Whatever students choose, the system will carry out automatic evaluation for the tested skill, and give effective instruction for them.

\section{The Implementation of the One-stop Virtual Experiment Platform}

The one-stop virtual experiment platform is constructed by the Industrial Training Center of Guangdong Polytechnic Normal University and is being used in the campus, which is funded by Guangdong Provincial Department of Education in 2015. There are twenty-two virtual experiments and training projects integrated in this platform, such as remote control for central air conditioning, high voltage control, virtual NC milling, educational electroacoustic system, virtual studio, non-isolation type AC-DC converter, three dimension logistics simulation, interactive virtual assembly, etc., which are relative to five majors: electronic engineering, automatic control, logistics management, digital media and machining. Most of these experiments and training involve dangerous or non-reversible operation, risky experimental condition or high trial cost, so we turn them into virtual experiments and training with VR technology in the platform to facilitate the vocational education.

The one-stop virtual experiment platform integrates teaching, learning and testing into the virtual educating environment. First, all the teaching resource is uploaded on the platform by teachers and well categorized for retrieval, and thus students can choose whatever they like to learn any time just like in class. Then students do 
experiment or carry out skill training in the virtual environment. No matter what they do in the virtual scene, the learning system will track their operation and give them real-time feedback and guidance [13]. Finally, students can take various types of test, such as professional level test, operation test, skill certification examination, etc.

Take an example. "Refrigeration equipment electrical fault detection intelligent examination system" is one part of the automatic test system. This system integrated training and testing. It provides four different refrigeration equipment control circuits for students to take simulation training as warm-up: 1) inverter air conditioner control circuit 2) heat pump type air conditioning control circuit 3) central air conditioning control circuit 4) cold storage control circuit. When testing, the system will set up a variety of intelligent fault points in these four circuits to check student's actual operation ability, which can distinguish different levels of their skill and thus grant them different grades of certificate [14-15].

Another example of automatic test system is "central air conditioning information intelligent examination system". Students can remotely access to central air conditioning virtual simulation interface (Figure $6 \&$ Figure 7) to execute simulation training, such as switching sequence for central air conditioning and cold storage, time delay control, running state real-time monitoring and troubleshooting, etc., and then take the skill certification examination [11].

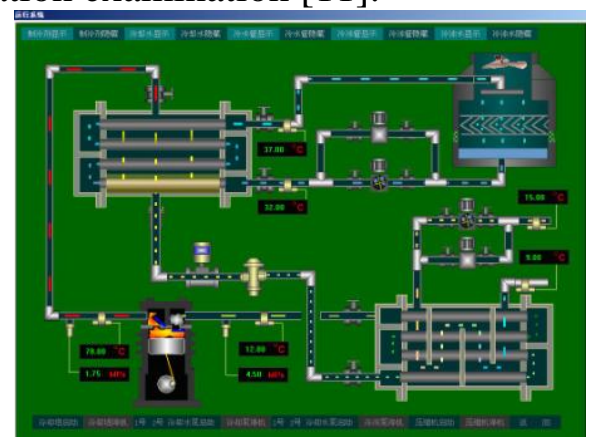

Figure 6. Virtual Training Interface for Central Air-conditioning

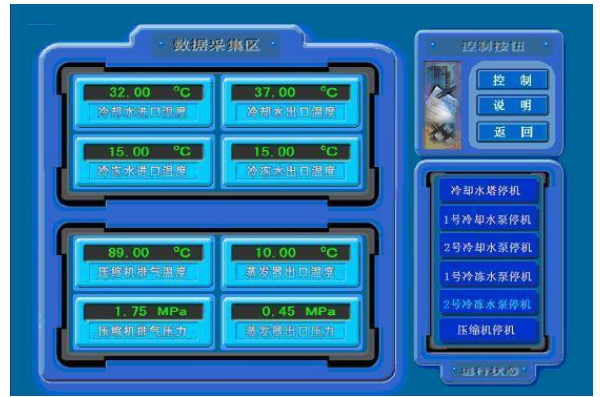

Figure 7. Central Air-conditioning Remote Control Simulation Interface

Up to now, more than two hundred students in Guangdong Polytechnic Normal University have passed skill certification examination through this platform and get the corresponding skill certificate. The one-stop virtual experiment platform is being further developed and is planned to provide more than sixty virtual experiments and training projects. Since more and more students need skill certificate to apply for job, this platform will add to twenty-eight kinds of skill certification examination involved the professions of numerical control, electronics, electrician, software, automobile, and finance, etc., in the future. Moreover, it is going to open to brother vocational institutions for wide use. Thus, it will attract more educators and experts to construct, develop and share the advance information education resource on the platform. 


\section{Conclusion}

In this paper, we build a comprehensive practice platform through information technology. The platform runs as the open and safe lab for students making practice anytime anywhere. Since the one-stop virtual experiment platform is also a comprehensive platform, students can take learning, training and testing on it. As all education recourse is digitalized and shared on the platform, it is accessible to the students distributed in different places. Practice has proved that this platform is a product of deep integration of information technology and practice teaching in education. It not only provides an innovative mode to solve the problem of the difficulty of student practice in current vocational education, but also serves as a shared and open education resource repository for all the students and educators.

\section{References}

[1] Information on http://www.yd56.com.cn/NewsView.aspx?id=54

[2] Ren Jianlan, Education and Occupation, 2015, pp. 43-44.

[3] Li Yumei, Li Qian, Popular Science and Technology, 2014, pp.142-144.

[4] Zhang Jing, Xiao Ming, China Electric Power Education, 2014, pp.176-178.

[5] Liu Yang, Cai Baosong, Continuing Education, 2015, pp.11-13.

[6] Hu Hang, Zhan Qinglong, Continuing Education, 2014, pp. 166-169.

[7] Chen Huajun, Zhao Shibin, Laboratory Research and Exploration, 2012, pp.158161.

[8] LI Hai-yan, ZHAO Han-qing, GAO Xing-hai, Laboratory Research and Exploration, 2009, pp.115-117.

[9] Zuo Yusheng, Lin Li, MengZhengda, Experimental Technology and Management, 2013, pp. 211-213.

[10]Chen Suhua, Wang Weimin, Huang He, Laboratory Research and Exploration, 2009, pp.142-144.

[11]Zhang Jin, Research on Electrochemical Education, 2005, pp.77-80.

[12]Liu Qiaoshou, Huang Peiyu, Laboratory Research and Exploration, 2013, pp.157-201.

[13]Lv Shoulin, Experimental Technology and Management, 2009, pp.157-159.

[14] Yuan Nanhui, Research on Electrochemical Education, 2007, pp.66-68.

[15] Wang Hang, Sun Qi, Modern Distance Education, 2010, pp.39-41. 